\title{
Energy saving and indoor air pollution in Italy: the radon problem
}

\begin{abstract}
Issues related to efficient energy use have eliminated the natural exchange of air through the building envelope, causing a greater concentration of indoor pollutants. One of them is radon, which seeps out due to the porosity of the soil and can accumulate indoors, penetrating basement cracks due to pressure differences. International studies claim that ten percent of all lung cancer cases can be attributed to radon exposure. The matter is well known from the medical and physical point of view; however, it is also a construction problem. Some building regulations in Italy include provisions to protect against radon's health risks, but the problem is still underestimated by designers. This paper shows some experimental prevention and remediation techniques for new and existing buildings in Italy.
\end{abstract}

Keywords: radon, indoor air pollution, energy saving, lung cancer, cleaning products, critical pollutants indoors,
Volume 2 Issue 3 - 2018

\section{Giovanni Zannoni}

Department of Architecture, University of Ferrara, Italy

Correspondence: Giovanni Zannoni, Department of Architecture, University of Ferrara, Italy,

Email giovanni.zannoni@unife.it

Received: March 16,2018 | Published: June 04, 2018

\section{Energy savings and indoor air pollution}

Issues related to the presence of indoor pollutants coming from cleaning products, furniture, surface finishes, appliances and equipment within buildings are well known, as well as the ones attributable to the lifestyles and habits of the inhabitants and household activities. Problems related to reducing energy consumption are equally well known, many of which tend to limit the convective exchanges between internal and external environments through the building envelope in order to limit heat dispersion. Nevertheless, these two aspects stand in direct opposition: by limiting (energy-consuming) natural convection, indoor air quality is entrusted to technical systems that are able to control parameters related to well-being, but that do not take into account the possible presence of pollutants. This is the case of the radioactive gas radon. Radon is probably one of the most critical pollutants indoors for various reasons. It is:

I. highly harmful (e.g. can cause of lung cancer)

II. colourless, odourless, tasteless

III. detectable only with special equipment

IV. produced independently from humans, plants or other aspects that are directly controllable and known

\section{Natural in origin (land).}

Despite knowing everything there is to know about this element from medical and physical points of view [i.e. the ASL (Italian Local Health Authorities) are aware of the issue because it is a public health problem and physicians know exactly where it comes from, how it is formed, how it moves, etc.], the responsibility for identifying effective forms of prevention must be shouldered by the construction industry. It is inside the house that radon becomes harmful and it is through the invisible permeability of the building envelope that this pollutant gets inside, further worsened by the fact that the building envelope (coupling to the ground) not only allows the incoming of radon but it also prevents its emission.

\section{A note on physics}

Isotopes that exist in nature in an unstable configuration, such as radon, are called radionuclides. They are present in water, rocks and soils and they originate from each other ("radioactive families") during the decay process. The uranium radioactive family includes radon, an isotope with a mass number of $222\left({ }^{222} \mathrm{Rn}\right)$. A noble gas, radon is natural, odourless and colourless and derived from the decay of uranium, i.e. the process by which a radioactive element is transformed into another substance emitting radiation. Uranium is present in almost all of the Earth's crust and thus in the soil, rocks, etc.

\section{Health effects}

After smoking, inhalation of radon is the second-most common cause of lung cancer. ${ }^{6}$ The International Agency for Research on Cancer (IARC) has included radon in group 1: definitely carcinogenic. In the tissues crossed during decay, ionizing radiation releases a considerable amount of energy that causes damage to DNA, a potential cause of the onset of cancer. For the most part, inhaled radon isotopes are exhaled or eliminated from the tracheobronchial mucociliary epithelium system, but, if present in high concentrations, it increases the risk that the emission of harmful particles during decay happens inside the respiratory system. Therefore, there is only an 'acceptable risk' (rather than a 'no risk') threshold. Human exposure to ionizing radiation from natural sources is an inescapable fact of life on Earth. However, it is estimated that about $50 \%$ of the average annual dose of radiation resulting from natural exposure comes from radon inhalation, which is precisely why we can and must control it.

\section{Techniques and measurement units}

Radon measurement is based on the number of Alpha particles emitted into the air by radon isotopes during the decay process. The measurement unit is the $\mathrm{Bq}$ (Becquerel), where one $\mathrm{Bq}$ is equivalent to the emission of a radioactive particle every second and is measured by cubic meter of volume $\left(\mathrm{Bq} / \mathrm{m}^{3}\right)$. Acceptable values are less than $200 \mathrm{~Bq} / \mathrm{m}^{3}$, i.e. 200 radioactive Alpha emissions per second per cubic meter. The integration measurement system is the most common, in 
addition to being reliable and rather inexpensive (€50-100 for each measurement point). It is carried out by placing a dosimeter the size of a small glass in the living area of the building's ground floor and leaving it for a set amount of time, depending to the type of dosimeter.

\section{How radon enters buildings}

Radon is an inert gas, free to migrate by molecular diffusion through the interstitial spaces of the soil, until it emerges from pores and cracks in the ground and disperses itself in the atmosphere. ${ }^{1}$ However, when radon encounters the basement of a building, it can easily penetrate minor cracks, connecting joints or cross points of plumbing, electrical and drainage pipes in the basement and accumulate inside living spaces. ${ }^{2}$ In fact, radon can be sucked inside a building by convection, i.e. due to movements of air that are triggered between ground and building due to the varied pressure between lower and upper spaces caused by thermal difference (stack effect), or as a result of the pressure of the wind against the building (Venturi effect). An inside/ outside temperature difference of $10{ }^{\circ} \mathrm{C}$ or a wind speed of $5 \mathrm{~m} / \mathrm{s}$ will produce a pressure difference of only five $\mathrm{Pa}$, sufficient enough to draw radon from the ground. This convective motion of the air is greater in winter, when heating systems are on (thermal difference between the ground and living spaces, i.e. the stack effect) and during the night, when all of the structure's openings are usually closed and the building envelope is more sealed. As a result, the radon that enters cannot get out. Limited autonomous movement ${ }^{3}$ characterizes radon isotopes; they are able to move mainly thanks to the presence of dust particles, aerosols, VOC (volatile organic compounds), water vapour, etc. in the air that transport them until they reach the respiratory system. They are then deposited on the mucous membranes and start to decay, releasing energy (hypothetical precursor of tumours/ biological damage). ${ }^{4}$ Many factors determine the degree of radon gas infiltration inside living spaces. They include:

I. The litho logical nature of the soil. Many ARPA (Italian Regional Environmental Protection Agencies) have mapped the risk areas (radon prone areas);

II. weather and barometric pressure;

III. Groundwater levels. Radon is soluble in water and can be conveyed from the aquifer; moreover, water occludes the interstices of the ground, pushing the gas upwards;

IV. contact between building and soil (type and construction technology of the basement);

V. presence of micro-cracks in the basement;

VI. un-sealed ducts passing through the basement;

VII. type of flooring in ground-level rooms (clay, discontinuous materials, wood);

VIII. permeation through building not compact or porous materials;

IX. permeability between floors of the building due to full height stairwells that allow the radon to pass to the upper floors;

$X$. the presence of chimneys, elevator shafts, bathroom and kitchen fan ducts, all of which increase the building's depression towards the ground;

XI. Some building characteristics (shape, size, the arrangement of openings, the location of the rooms in relation to the ground, orientation and exposure, etc.). ${ }^{5}$

XII. How the building is used.

\section{Tips for prevention in new construction}

Although radon is a radioactive gas, with the fears this term can raise protection methods against this pollutant are simple, inexpensive and easy to implement if the designer is aware of the risk. Since the main source of gas is the soil and the main way radon enters the building is through the foundation, the basement is the main point of intervention. In new constructions, it is sufficient to put a membrane (bitumen, polyethylene, PVC) between the ground floor and the foundation. This membrane may be the same used to prevent capillary moisture from rising. It must be applied over the entire footprint of the building, below the masonry (including structural) and sealed around the structural elements that it cannot be placed underneath (e.g. pillars). It must be sealed around the ducts crossing the basement, avoiding breakages due to foot impact during installation. Small holes do not constitute problems for moisture, but they could create gas passage points. Anti-radon certified membranes that are good, reliable and highly resistant to breakage are available at an average cost of 6 to 8 Euros per square meter. A 'vapour barrier' membrane, however, is already an effective protective layer, if placed carefully. BRE (British Research Establishment) manuals also suggest simply using a thick polyethylene membrane (Figure 1). ${ }^{3}$ Another solution is the construction of a ventilated crawl space below the basement, especially in radon prone areas, to prevent gas from entering the house. The air passage within this inter space can draw gas by vacuum against the ground, thanks to wind effects and the temperature gradient, dispersing it in the atmosphere. The gas is not emitted from the ground 'under pressure', but due to modest differences in temperature and atmospheric pressure. The crawl space should be clear and empty, with openings on the north and south facades (Figure 2). Some construction regulations already require a compulsory crawl space for new buildings in radon risk areas. ${ }^{6}$

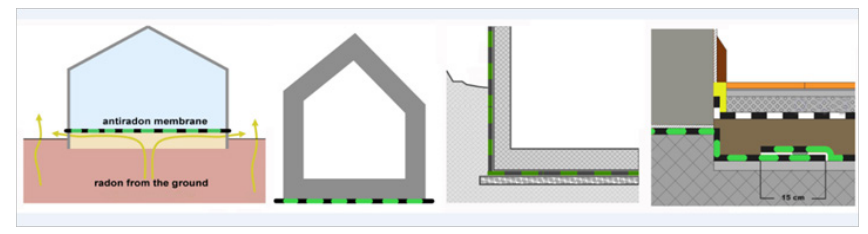

Figure I Preventing techniques: a membrane has been laying between the building and the ground, eventually also along vertical wall against ground. The sheets are overlap of about $15 \mathrm{~cm}$ and sealed and they must go under vertical walls.

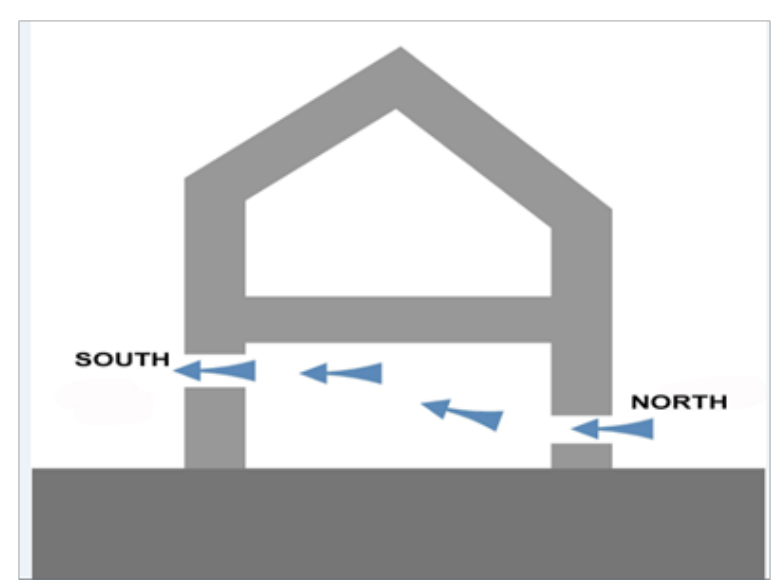

Figure 2 Preventing and remediation technique: if a free crawl space under the building exist, some openings on the north-south facades can be realized and the air passage within this interspace can suck and dispersing radon in atmosphere. 
In critical areas or those where the realization of a crawl space is not possible for urban-architectural-structural reasons, one possible solution is to provide a sump below the basement, as barycentric to the building as possible (5). This sump point consists of a simple concrete cube, similar to that of underground sewerage, which must be connected to a PVC pipe $(\varnothing 100 / 120 \mathrm{~mm})$ that extends to the perimeter of the building, where the pipe will be inserted into a second, similar concrete cube (Figure 3). This system does not prevent radon gas from entering; instead, it is simply a preparation system. Once construction is finished, the indoor gas concentration is measured. If it is below the risk threshold, this system (at a modest cost) will be abandoned. If the concentration is above the risk level, in the perimeter of the concrete cube, a fan will be placed that, through the existing pipe, will depress the point under the building so as to create a suction effect towards the ground (depressurization). The aim is to create artificial depressurization greater than that triggered by the building, capturing and evacuating the gas before it is drawn inside the building.?

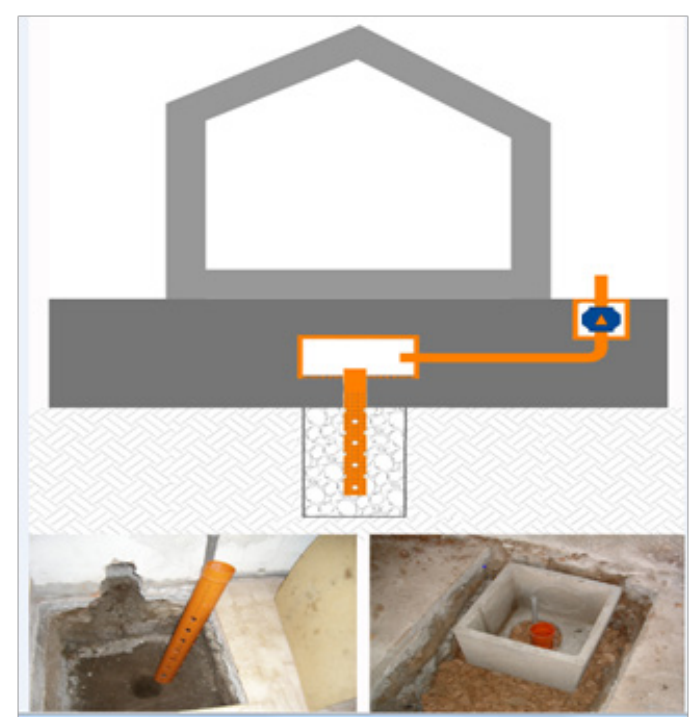

Figure 3 Preventing and remediation technique: if a crawl space does not exist, a suction point as much as possible barycentric to the building can be realized, connecting with a PVC tube to an external fan.

\section{Tips for the remediation of existing buildings}

Remediation techniques do not differ from those already in use, at least from the theoretical point of view. If a crawl space exists, it is possible to make a hole in the perimeter wall and connect a fan, thereby creating a vacuum in the crawl space (Figure 4). The crawl space then behaves as a large suction point beneath the house. The system is effective also if the crawl space is partially filled with debris. On the contrary, it does not work if it is filled with compacted material (mortar residue, "washes" of concrete mixers, clay, etc.) or if there are structural elements (e.g. curbs) which limit the suction action to a few zones only. Once the hole has been opened, the crawl space should be inspected and the possibility to ventilate it evaluated. Large buildings require more suction points, which must always be created on the same side and never on opposing sides. If there is no crawl space, a suction point can be created with a PVC pipe $(\varnothing 100 / 120 \mathrm{~mm}$, drilled on the perimeter), protected by a nonwoven-fabric and driven into the ground below the building (Figure 3). If it is not possible to place the suction point inside the house (depending on the use of the ground floor), the PVC pipe and the fan can be placed just outside the building (Figure 5). In this case, consider the possibility of creating more suction points depending of the size of the building. 50-60 watt vacuums with flows of 500-600 cubic meter/hour are functional in most cases, timing their operation in order to save energy. In all cases, it is advisable to avoid the problems seen before, and thus seal any ducts in the basement, close flues and fans when not in use, seal the elevator shaft or the coupling to the ground of full height stairwells, etc. ${ }^{8}$
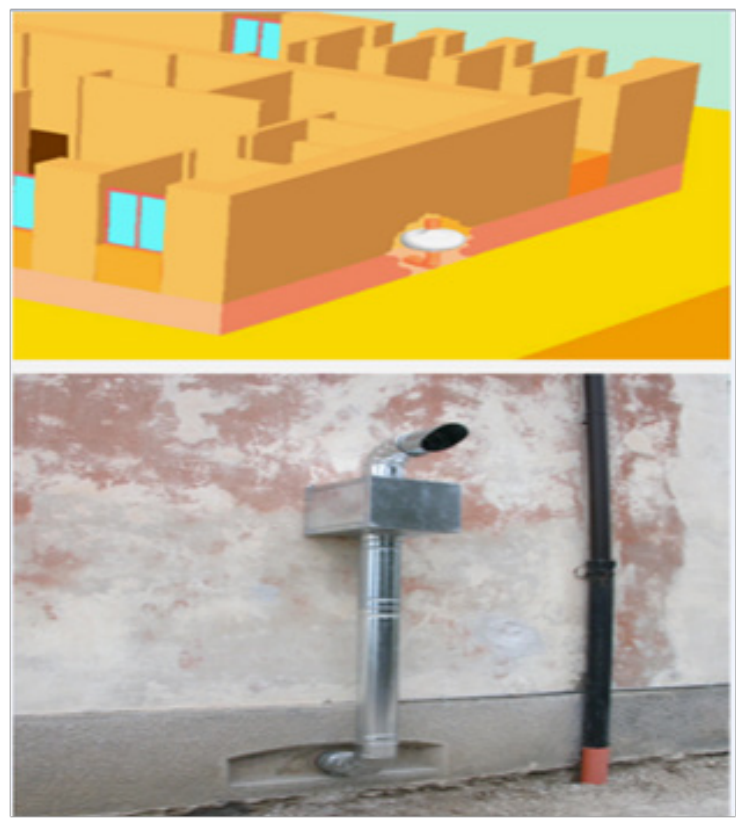

Figure 4 Preventing and remediation technique: if a passive-ventilation solution is not feasible, a mechanical suction point can be apply to the crawl space by a fan.
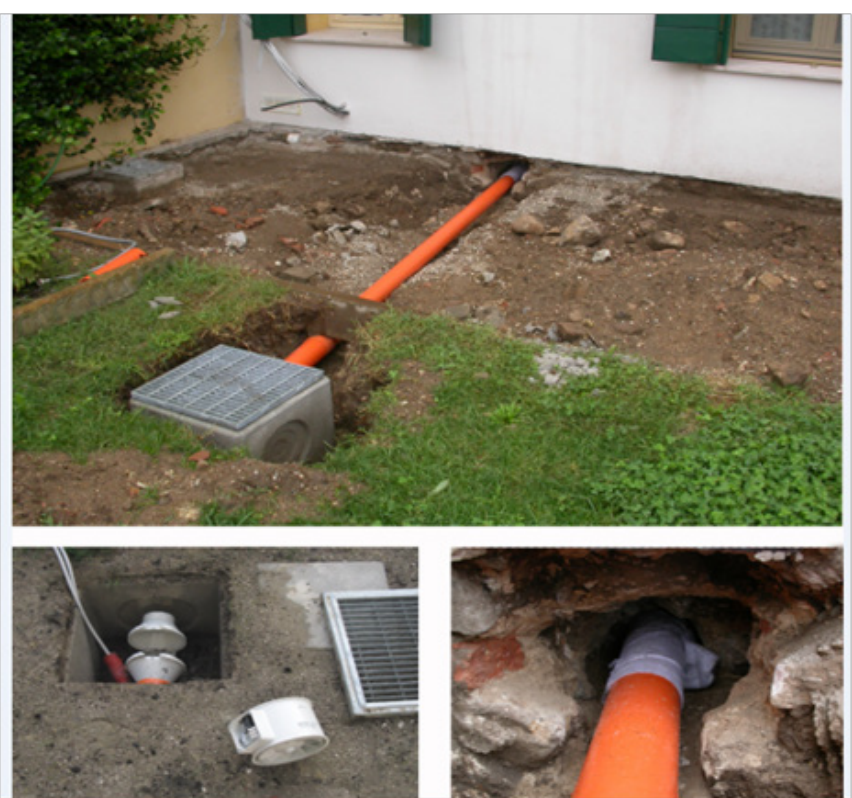

Figure 5 Remediation technique via outer suction point: a PVC pipe coated with non-woven fabric is driven into the ground under the building and then channelled to a fan located in external concrete cube. 


\section{Conclusion}

The experience gained from these research activities, including on large buildings, makes it possible to verify the validity of the techniques briefly presented above. During the research phase, the need to provide at least two remediation techniques on the same building or to apply the same technique twice in different points was deemed necessary. The size of a building and its volumetric complexity has often obliged researchers to consider the construction as composed of two or more blocks (Figure 6) and thus adopt several solutions. The most widely used technique was depressurization of a crawl space, followed by depressurization of the ground via a suction point. The most complex aspect dealt with was often the position of the suction system, a pain point that often led to exhausting "negotiations" with users not yet sufficiently aware of the problem objecting to the "aesthetic invasiveness" of the system. Even more complex was the intervention in energy-saving buildings where the chosen radon remediation technique potentially interacted with energy efficiency and vice versa, showing how these two aspects must always be considered together. To avoid wasting energy, the air tightness of the house is often not enough to prevent radon entry and, at the same time, also not enough to prevent the heat loss caused by a radon remediation system that causes depressurization in the basement, even if only a few Pascal's. Aspects of energy saving and welfare, which usually only concern air movement, temperature and humidity, must expand to a greater focus on air quality. If left unchecked, the health problems that arise due to indoor pollutants (and their personal and social costs) are soon likely to be more expensive than the highest levels of energy consumption seen in the past.

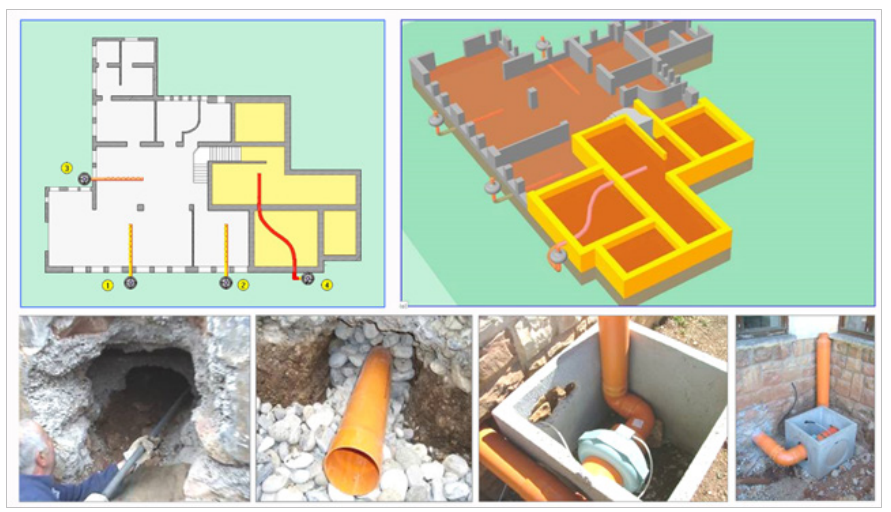

Figure 6 The size and volumetric complexity of the buildings needs sometime more suction points. Three pipes were inserted horizontally under the basement in a pit filled with gravel to enlarge the suction surface and then channelled to an outside suction point with fan.The fourth fan was channelled to a flexible PVC pipe inserted inside the existing crawl space.

\section{Notes}

This phenomenon leads to an atmosphere background value for Italy of about $10-15 \mathrm{~Bq} / \mathrm{m}^{2}$. Soil is considered the leading source of radon, but some building materials can be radon-emitters also, such as tuff, granite, etc. At the moment of decay and emission of a radioactive Alpha particle, the radon isotope 'recoils' in the opposite direction for the insignificant distance of approximately 0.05 microns. Some of radon isotopes move by 'clinging' to particles in the air, but it is the unattached fraction that produces the most damage, penetrating deeper into the lungs. Each suction point has an action radius of 6-8 meter depending on the soil type.

\section{Acknowledgements}

None.

\section{Conflict of interest}

The author declares there is no conflict of interest.

\section{References}

1. ARPA Friuli Venezia Giulia, (undated), Indicazioni e proposte per la protezione degli edifici dal radon, ARPA, Udine.

2. Regione Lombardia Sanità, ASL Lombardia, Arpa Lombardia, et al. Linee guida per la prevenzione delle esposizioni al gas radon in ambienti indoor. Milano, 2011. p. 1-53.

3. Scivyer C. Guidance on protective measures for new buildings. Brepress, Bracknell, 2007.

4. Scivyer C, Cripps A. A BRE guide to radon remedial measures in existing dwellings. Brepress, Bracknell, 1998.

5. Ufficio federale della sanità pubblica. Radon: guida tecnica, Berna, 1990.

6. WHO-World Health Organization. WHO handbook on indoor radon, a public health perspective. WHO Press, Geneva, 2009.

7. Zannoni G. Gas radon, Tecniche di mitigazione, Edicom. Monfalcone, 2006.

8. Zannoni G, Bigliotto C. Gas radon, Monitoraggio e bonifica, Edicom, Monfalcone, 2008. 